\title{
Mensuração de perdas de pós-colheita na cadeia de suprimento de moageiras do trigo no Rio Grande do Sul
}

\author{
Fernando Vinícius da Rocha* \\ Thiago Guilherme Péra** \\ Daniela Bacchi Bartholomeu $u^{* * * * *}$ \\ José Vicente Caixeta Filho******
}

\section{Resumo}

Este artigo tem como principal objetivo mensurar as perdas físicas e econômicas observadas na cadeia de suprimentos das moageiras de trigo do Rio Grande do Sul (RS). A partir da aplicação de questionário com representativos agentes do setor, a cadeia logística do trigo no RS foi caracterizada e as perdas do produto em cada etapa da cadeia foram quantificadas. Para os fluxos de transporte característicos de mercado interno, as perdas representam $11,41 \%$ da quantidade total de trigo em grão oriundos das fazendas. Destacam-se, neste contexto, as perdas na colheita e na armazenagem junto às cooperativas $(93,55 \%$ das perdas totais). A monetização de perdas físicas decorrentes totaliza um valor de $\mathrm{R} \$ 119,4$ milhões. Baseado nos resultados obtidos, são sugeridas estratégias para mitigação das perdas de trigo nos diferentes elos da cadeia logística.

Palavras-chave: Cadeia logística. Perdas no pós-colheita. Segurança alimentar. Trigo.

* Doutorando em Economia Aplicada pela Escola Superior de Agricultura "Luiz de Queiroz" (Esalq/ USP) e pesquisador do Grupo de Pesquisa e Extensão em Logística Agroindustrial (Esalq-LOG). E-mail: fernando.vinicius.rocha@usp.br

** Coordenador e pesquisador do Grupo de Pesquisa e Extensão em Logística Agroindustrial (Esalq-LOG).E-mail: thiago.pera@usp.br

*** Pós-doutoranda do Núcleo de Apoio à Pesquisa (NAP) - Centro de Inovação em Logística Sustentável (CALS) da Escola Politécnica da USP (EPUSP) e pesquisadora do Grupo de Pesquisa e Extensão em Logística Agroindustrial (Esalq-LOG), Escola Superior de Agricultura "Luiz de Queiroz" (Esalq/ USP). E-mail: daniela.bartholomeu@usp.br

***** Professor Titular da Escola Superior de Agricultura "Luiz de Queiroz" (Esalq/USP) e coordenador do Grupo de Pesquisa e Extensão em Logística Agroindustrial (Esalq-LOG). E-mail: jose.caixeta@usp.br

http://dx.doi.org/10.5335/rtee.v23i48.7368

Submissão: 14/07/2016. Aceite: 16/02/2017. 


\section{Introdução}

Cerca de uma a cada quatro calorias deixam de ser consumidas pelos humanos em função de perdas que ocorrem ao longo dos estágios da cadeia produtiva de diversos tipos de alimentos. Segundo dados de Lipinski et al. (2013), por volta de $24 \%$ das perdas ocorrem na produção, $24 \%$ no manuseio e no armazenamento, $4 \%$ no processamento e na embalagem, $12 \%$ na comercialização e na distribuição e $35 \%$ no consumo.

Durante a produção ou a colheita, as perdas podem ser decorrentes, por exemplo, de quedas de grãos no campo em função dos equipamentos utilizados ou do descarte de hortifrútis devido à qualidade fora dos padrões. Durante o manuseio e o armazenamento, perdas ocorrem devido à presença de pestes, fungos e doenças. Durante o processamento e embalagem, frutas impróprias e peixes estragados são descartados. Alimentos processados também podem apresentar perdas em função de ineficiências no processo industrial. Na distribuição e comercialização, prazos de validade vencidos ou baixa qualidade do produto podem implicar perdas. Finalmente, durante o consumo, o desperdício acaba gerando outras perdas de alimentos.

Especificamente nas etapas de transporte, as perdas podem ocorrer por influência de diversos fatores, mas o motivo mais representativo está relacionado a problemas de infraestrutura, como, por exemplo, às más condições das estradas e à idade avançada dos veículos. Estradas em melhores condições, a disponibilidade de modais alternativos para a realização do transporte e, até mesmo, a existência de estruturas de armazenagem apropriadas são elementos importantes na redução de perdas de alimentos ao longo da cadeia de transporte.

No Brasil, mais de $60 \%$ do transporte de carga do país é realizado por rodovias, havendo, dessa forma, grande dependência dessa modalidade de transporte. Dos 1,6 milhões de quilômetros de rodovias existente, apenas 221 mil quilômetros são pavimentados. A CNT (2014) ainda aponta que 49,9\% do sistema rodoviário brasileiro pavimentado está em mal estado de conservação. Além disso, a frota brasileira de caminhões tem uma idade média superior a 17 anos, e existe um déficit na capacidade estática de armazenagem no país, principalmente no que diz respeito a produtos agrícolas.

As perdas de alimentos podem ser qualitativas ou quantitativas. Perdas quantitativas estão relacionadas a perdas em termos físicos, passíveis de avaliação e mensuração, tais como redução no peso e no volume. Já as perdas qualitativas estão relacionadas ao valor nutricional e requerem formas diferentes de avaliação. Independentemente do tipo de perda, tem-se uma menor disponibilidade de 
alimento para a população, tornando-se necessário produzir mais para compensar tais perdas.

Neste sentido, a redução das perdas torna-se uma estratégia "ganha-ganha", pois, além de aumentar a disponibilidade de alimento e, portanto, contribuir para a segurança alimentar, também acaba por reduzir a pressão sobre o ambiente, especialmente sobre os ecossistemas, o clima e a água.

Este artigo tem como principal objetivo caracterizar e mensurar as perdas existentes ao longo da cadeia logística do trigo no Rio Grande do Sul (RS), estado brasileiro responsável por quase metade da produção nacional do grão, bem como estimar as perdas físicas e econômicas em cada elo da cadeia de suprimentos das moageiras do RS. Além da importância do Rio Grande do Sul na produção do trigo, destaca-se o fato de a produção ser caracterizada por muitas e pequenas unidades produtoras, além da presença importante de cooperativas na cadeia logística. A partir dos resultados obtidos neste estudo, são sugeridas estratégias para redução de perdas de alimentos nos diferentes elos da cadeia logística.

\section{Revisão de literatura}

\subsection{Perdas na cadeia de suprimentos e segurança alimentar}

Estudos indicam que a produção mundial de alimento deve aumentar cerca de $70 \%$ para que seja possível alimentar a população em 2050. Entretanto, os recursos limitados, como terras aráveis, água e energia, podem impor sérias dificuldades para que a produção de alimentos responda a esta necessidade. Nesse sentido, a segurança alimentar ganha importância devido ao aumento da população e à escassez de tais recursos naturais. Bourne (1977) recomenda três maneiras de atingir um nível adequado de segurança alimentar: (i) aumento de terras aráveis; (ii) aumento da produtividade através do uso intensivo de tecnologia; e (iii) aumento de estações de crescimento por ano. No entanto, outro foco alternativo importante é a redução de perdas de pós-colheita dentro das operações envolvendo o produtor rural e o consumidor, ampliando a oferta de alimentos e consequentes reduções dos preços dos mesmos (LIPINSKI et al., 2013).

Sabe-se que o agronegócio brasileiro tem tido êxito neste contexto, uma vez que os níveis de produtividade alcançados nas últimas décadas ilustram o papel ativo da produção "dentro da porteira". Entretanto, enquanto os processos produtivos 
têm sido extremamente competitivos, tal competitividade é perdida nas diversas etapas do pós-colheita, ao longo da distribuição.

As estimativas de perdas de alimentos diferem bastante entre os estudos já realizados, inclusive em âmbito internacional. Além disso, a ausência de dados e as informações desatualizadas dificultam comparações entre diferentes regiões e tipos de produtos. De qualquer forma, Parfitt, Barthel e Macnaughton (2010) destacam que é importante distinguir as perdas de alimentos perecíveis e não perecíveis, já que essas possuem características e causas bastante diferentes.

No caso de alimentos não perecíveis, como milho, trigo, arroz e soja, por exemplo, as perdas em países desenvolvidos são significativamente mais baixas (entre $0,07 \%$ e $2,81 \%$ ) do que as verificadas nos países em desenvolvimento (SMIL, 2004, apud PARFITT; BARTHEL; MACNAUGHTON, 2010). Os autores indicam que, em função de grande parte da produção de grão acabar sendo armazenada, muitos estudos focam nas perdas durante esta etapa. É o caso, por exemplo, do estudo de Silva et al. (2003a), que modelou as perdas causadas por Sitophilus zeamais e Rhyzopertha dominica em trigo armazenado. De qualquer forma, mesmo nesses casos, há uma grande dificuldade de mensuração, especialmente relativa às perdas qualitativas.

Um estudo publicado pela FAO (2011) e citado por Belik, Cunha e Costa (2012), estimou os padrões de perdas alimentares no mundo para diversos grupos de produtos ao longo da cadeia de produção e consumo. A Tabela 1 apresenta as perdas alimentares ao longo das principais etapas da cadeia de produção e distribuição.

Tabela 1 - Perdas estimadas para grupos de produtos por etapa da cadeia produtiva na América Latina (em \%)

\begin{tabular}{l|r|r|r|r|r}
\hline Grupos de Produtos & $\begin{array}{c}\text { Produção } \\
\text { agrícola }\end{array}$ & $\begin{array}{c}\text { Manejo e } \\
\text { estocagem }\end{array}$ & $\begin{array}{c}\text { Processamento } \\
\text { e embalagem }\end{array}$ & Distribuição & $\begin{array}{c}\text { Consumo } \\
\text { Doméstico }\end{array}$ \\
\hline Cereais & 6,0 & 4,0 & 2,0 a 7,0 & 4,0 & 10,0 \\
Raízes e tubérculos & 14,0 & 14,0 & 12,0 & 3,0 & 4,0 \\
Oleaginosas e & 6,0 & 3,0 & 8,0 & 2,0 & 2,0 \\
leguminosas & 20,0 & 10,0 & 20,0 & 12,0 & 10,0 \\
Frutas e vegetais & 5,3 & 1,1 & 5,0 & 5,0 & 6,0 \\
Carne & 5,7 & 5,0 & 9,0 & 10,0 & 4,0 \\
Peixes e frutos do mar & 3,5 & 6,0 & 2,0 & 8,0 & 4,0 \\
\hline Leite & & & &
\end{tabular}

Fonte: Gustavsson, Cederberg e Sonesson (2011 apud BELIK; CUNHA; COSTA, 2012). 
No Brasil, conforme Chitarra e Chitarra (2005 apud BELIK; CUNHA; COSTA, 2012), as estimativas de perdas pós-colheita para produtos com maior durabilidade, como grãos e cereais, estão na faixa de 5\% a 30\%. De fato, o levantamento realizado por Parfitt, Barthel e Macnaughton (2010) aponta que as perdas de arroz no pós-colheita variam entre $1 \%$ e $30 \%$.

Para os hortifrutícolas, uma série de estudos foi realizada, considerando diferentes etapas da cadeia de produção e de distribuição dos produtos. Caixeta-Filho (1999), citando dados da Secretaria da Agricultura e Abastecimento de São Paulo (1993), sugere que as perdas físicas de banana e tomate, por exemplo, são da ordem de $40 \%$ da produção, enquanto as perdas de laranja, uva, manga e pepino ficam entre $22 \%$ e $28 \%$. Um estudo mais recente aponta perdas na ordem de $17,7 \%$ na cadeia produtiva do tomate, $21 \%$ na da banana prata e $31,3 \%$ na da banana nanica (CEASAMINAS, 2008 apud BELIK; CUNHA; COSTA, 2012).

No caso do tomate, O'Brien (1980 apud GAMEIRO et al., 2008), estima que as perdas no suprimento de tomate na Califórnia, do campo até o processamento industrial, podem atingir $12 \%$, e são decorrentes do excesso de impactos físicos que recebe durante o processo. $\mathrm{O}$ autor também afirma que a colheita realizada em períodos mais quentes do dia provoca perdas maiores nas cargas que chegam à fábrica quando comparada àquela realizada logo no início da manhã. Para Moretti et al. (2000 apud GAMEIRO et al., 2008), as perdas durante o transporte situam-se entre $2 \%$ e $3 \%$ quando a cultivar de tomate para processamento é colhida no ponto correto de maturação; por outro lado, as perdas durante o transporte podem chegar a cerca de $5 \%$ se os frutos são colhidos muito maduros.

Já Silva et al. (2003b), Tofanelli et al. (2007) e Perosa, Silva e Perosa (2009) são exemplos de estudos que enfocam as perdas de frutas no mercado varejista. As perdas estimadas variam de $3,2 \%$ a $15 \%$ nessa etapa, dependendo do tipo de fruta e do local de comercialização.

Assim, no agronegócio, benefícios para a segurança alimentar podem decorrer não somente de um aumento na produção, mas também ao se evitar perdas que ocorrem ao longo da cadeia logística. Mais especificamente, melhores condições de rodovias, maior disponibilidade de modalidades de transporte alternativas ou mesmo uma infraestrutura de armazenagem adequada, por exemplo, além de reduzir custos de movimentação do produto, também devem minimizar possíveis perdas ao longo dessa movimentação. Os resultados devem beneficiar desde fazendeiros, até agentes envolvidos com a operação de transporte e, finalmente, os consumidores.

$\mathrm{O}$ conceito de perda pode ser analisado tanto do ponto de vista quantitativo quanto qualitativo. Perdas quantitativas são aquelas relacionadas à diminuição do 
peso do produto ao longo das etapas logísticas, ou decorrentes de danos causados por ataques de insetos, roedores ou, até mesmo, por condições naturais adversas, como precipitação, condições de umidade, temperatura etc. As perdas qualitativas, por sua vez, são representadas pela modificação das características do produto (GAMEIRO et al., 2008).

Perdas quantitativas e qualitativas de produtos agrícolas, devido a condições inapropriadas de transporte e armazenagem entre a unidade produtora e receptora, talvez sejam a forma mais direta e evidente. Entretanto, uma série de outros tipos de perdas pode ser observada durante a logística de transporte e armazenagem de produtos agrícolas.

Perdas econômicas decorrentes de um transporte ineficiente e de uma estrutura de armazenagem deficitária são extremamente relevantes e, em grande parte dos casos, muito difíceis de serem identificadas e mensuradas. A utilização de veículos ou embalagens inadequadas, a falta de opção de modalidades alternativas de transporte, o tempo gasto em filas, a necessidade de escoar o produto em períodos de aquecimento do frete, entre outras, são exemplos de perdas econômicas que devem ser consideradas quando se analisa logística no pós-colheita.

Perdas ambientais relacionadas ao transporte são evidentes quando a ineficiência do sistema de transporte reflete em baixa produtividade dos veículos, maior taxa de consumo de combustível e, por consequência, maior dependência energética. São também decorrência do impacto da qualidade da infraestrutura no transporte dos alimentos.

As perdas no transporte de produtos agrícolas ocorrem por diversos fatores, mas, em sua maioria, estão relacionadas às falhas no setor de infraestrutura, tal como a má conservação das estradas. Além disso, condições climáticas adversas, elevado transit-time, excesso de espera para carga e/ou descarga e características das condições do transbordo também podem implicar perdas de umidade e, consequentemente, de peso.

Em geral, a questão das perdas no pós-colheita tem sido avaliada de forma pontual. Embora seja reconhecida a importância dos efeitos sistêmicos transmitidos ao longo da cadeia produtiva, os estudos técnicos apontam a dificuldade de mensurar estes impactos (BELIK; CUNHA; COSTA, 2012).

\subsection{A produção de trigo no Rio Grande do Sul}

O trigo é o terceiro cereal mais produzido no mundo, ficando atrás apenas da produção de milho e de arroz (FAO, 2015). Sua produção é distribuída por países 
dos cinco continentes, e a China, a Índia e os Estados Unidos são os três principais produtores dessa cultura (FAO, 2015). O Brasil ocupa a vigésima-terceira posição no ranking mundial dos maiores produtores (FAO, 2015), com sua produção sendo superior a 4,3 milhões de toneladas (CONAB, 2014).

Ainda sobre o cenário mundial dessa cultura, o Brasil tem uma elevada dependência do trigo produzido no mercado externo. Segundo a FAO, o Brasil foi o segundo país que mais importou trigo no mundo, importando um volume de aproximadamente 6,5 milhões de toneladas do cereal (FAO, 2015), conforme mostra a Tabela 2.

Tabela 2 - Ranking dos países que mais importam trigo

\begin{tabular}{c|l|c}
\hline Ranking & \multicolumn{1}{|c|}{ País } & Quantidade Importada (t) \\
\hline $1^{\circ}$ & Egito & $11.428 .301,00$ \\
$2^{\circ}$ & Brasil & $6.580 .434,00$ \\
$3^{\circ}$ & Argélia & $6.347 .232,00$ \\
$4^{0}$ & Indonésia & $6.250 .490,00$ \\
$5^{\circ}$ & Itália & $6.108 .562,00$ \\
\hline
\end{tabular}

Fonte: FAO (2015).

Em termos gerais, o abastecimento interno de trigo é muito dependente de importações, e o Brasil não possui exportações significativas desse cereal, objetivando ainda sua autossuficiência (MAPA, 2015).

Em território brasileiro, a produção é concentrada nos estados da região sul do país, sendo o Rio Grande do Sul o principal produtor desse cereal, respondendo pela produção de mais de $43 \%$ do total nacional (CONAB, 2014). De uma forma geral, a produção de trigo está basicamente distribuída por todo o estado, sendo, entretanto, mais concentrada na região Noroeste do estado. Pertinente à área cultivada com trigo, esta é da ordem de 976 mil hectares, o que representa 51,5\% do total de área destinada à produção de trigo do país, conforme pode ser observado pela Tabela 3 .

Tabela 3 - Área, produção e produtividade de trigo no estado do RS, safra 2012/2013

\begin{tabular}{c|c|c|c|c|c}
\hline \multicolumn{2}{c|}{ Área (mil ha) } & \multicolumn{2}{c|}{ Produção (mil t) } & \multicolumn{2}{c}{ Produtividade (kg/ha) } \\
\hline Estado RS & $\%$ Brasil & Estado RS & $\%$ Brasil & Estado RS & Brasil \\
\hline 976 & $51,5 \%$ & 1.894 & $43,3 \%$ & 1.941 & 2.311 \\
\hline
\end{tabular}

Fonte: CONAB (2014). 
Em uma breve caracterização da produção gaúcha, dados do IBGE (2006) mostram que o estado do Rio Grande do Sul possui 441.472 unidades de produção agrícola, as quais ocupam 20 milhões de hectares. As unidades produtoras são predominantemente compostas por pequenas propriedades, sendo que mais de $87 \%$ delas são menores que 50 ha. Tais dados sugerem uma importância acentuada do cooperativismo na região, entre outras razões, por possibilitar ganhos aos produtores em termos de preço de venda, crédito e assistência técnica (MARSCHALL, 2009).

Ainda sobre a cadeia tritícola, é importante destacar a capacidade instalada para moagem de trigo no Rio Grande do Sul. Estima-se que o Brasil tenha um total de 201 moinhos em atividade (ABITRIGO, 2015). Desse total, 73,63\% dos moinhos estão localizados na região Sul do país. O estado do Rio Grande do Sul conta com um total de 57 moinhos, 28,36\% do total de empresas moageiras de trigo em território brasileiro (ABITRIGO, 2015). Tais moinhos dão ao estado uma capacidade de moagem equivalente a 1,8 milhões de toneladas de trigo, que corresponde a $16,3 \%$ da capacidade total de moagem do país, e ressaltam a importância desse estado na cadeia produtiva desse cereal.

\section{Material e métodos}

A presente pesquisa é caracterizada como exploratória e descritiva, de acordo com as definições propostas por Gil (1999). Exploratória pelo fato de os estudos focados na mensuração de perdas no pós-colheita serem escassos na literatura. Trata-se, portanto, de uma área de conhecimento que ainda carece de informações. Os traços descritivos são decorrentes do fato de a pesquisa buscar descrever o funcionamento da cadeia do trigo no Rio Grande do Sul, dos locais de produção até os locais de processamento do cereal.

A metodologia consiste em duas abordagens. A primeira é a realização de uma pesquisa de campo através da aplicação de questionários com agentes do setor, visando levantar as relações de perdas nos elos da cadeia de suprimentos de trigo para as moageiras no RS. A segunda diz respeito à estimação das perdas físicas e econômicas de tal cadeia, baseada em informações levantadas na primeira abordagem. 


\subsection{Pesquisa de campo}

Essa primeira abordagem da pesquisa foi subdividida em duas etapas. Na primeira, foi realizada ampla revisão de literatura, buscando principalmente caracterizar a cadeia do trigo no Brasil e, em especial, no Rio Grande do Sul. Esta primeira etapa foi importante para identificar e definir os agentes a serem entrevistados na etapa seguinte do estudo, relativa à pesquisa de campo e ao levantamento de dados primários que respondessem aos objetivos aqui propostos.

O uso de questionário na pesquisa de campo é sugerida por diversos autores, como Gil (1999), Hair Jr. et al. (2005) e Severino (2007), e sua aplicação foi a metodologia escolhida para o levantamento de dados da pesquisa. A construção do questionário, bem como do conjunto de questões, foi reflexo do perfil da amostra pesquisada e, nesse sentido, optou-se pela elaboração de dois tipos de questionários: (i) questionários para as cooperativas e moinhos de trigo; (ii) questionários para as empresas transportadoras e demais agentes atuantes na cadeia logística.

As questões foram formuladas todas centradas no objeto de estudo, de modo a serem compreendidas pelos respondentes (SEVERINO, 2007). Destaca-se, nesse sentido, a grande importância da primeira fase da pesquisa, relativa à revisão de literatura, para o efetivo preparo e realização das entrevistas. Os questionários foram compostos por 19 questões do tipo aberta, e foram aplicados através da realização de entrevistas pessoais.

Outro ponto de destaque foi a realização de um pré-teste antes da aplicação efetiva dos questionários, cujo objetivo foi o de assegurar a validade e a precisão deste instrumento de pesquisa (GIL, 1999).

A amostra utilizada na presente pesquisa foi não probabilística, ou seja, foi previamente definida em decorrência da importância e representatividade dos agentes na cadeia do trigo do Rio Grande do Sul. Esse tipo de amostra, segundo Hair Jr. et al. (2005), é classificada como "amostragem por conveniência".

Um total de treze agentes atuantes na cadeia logística do trigo em grão no estado do Rio Grande do Sul foi entrevistado: cinco transportadoras rodoviárias de cargas, três moinhos de trigo, duas cooperativas, dois terminais portuários/traders, e um sindicato de produtores rurais. Durante a pesquisa de campo, foram visitados seis municípios no estado do RS e percorridos quase 950 quilômetros. 


\subsection{Estimativas das perdas físicas e econômicas da cadeia de suprimentos do trigo}

Após a pesquisa de campo realizada para levantamento de dados primários sobre as perdas de trigo, foi estruturado um modelo para estimativas de perdas físicas e econômicas na cadeia de suprimentos das moageiras de trigo, envolvendo os seguintes elos: "fazenda $\rightarrow$ transporte T1 (fluxo logístico de trigo entre fazendas e cooperativa) $\rightarrow$ cooperativa $\rightarrow$ transporte T2 (fluxo logístico de trigo entre cooperativa e moinhos) $\rightarrow$ moinhos".

As estimativas foram baseadas na demanda de processamento das moageiras de trigo no RS, descontada a quantidade importada. Dessa forma, a quantidade de trigo demandada na cadeia de suprimentos das moageiras pelo próprio estado é na ordem de 1,680 milhão de tonelada (ABITRIGO, 2015).

A equação 1 quantifica as perdas físicas para cada elo $k$ baseado na quantidade inicial de trigo. Dessa forma, a quantidade inicial da fazenda foi dimensionada para atender à demanda das moageiras.

$$
\text { PFisica }_{k}=p r_{k} x Q I_{k}, \quad \forall k
$$

Onde:

Índices $k$ : elos da cadeia de suprimentos de trigo (fazenda, transporte T1, cooperativa e transporte T2);

PFisica $_{k}$ é a perda física no elo $k$, em toneladas;

$p r_{k}$ é a perda relativa em percentagem estimada com base na pesquisa de campo para cada elo $k$;

$Q I_{k}$ é a quantidade inicial de trigo no elo $k$, em toneladas.

A equação 2 quantifica a quantidade final de trigo no elo $k$, descontando a perda física existente no elo.

$$
Q F_{k}=Q I_{k}-\text { PFisica }_{k}, \quad \forall k
$$

Onde:

$Q F_{k}$ é a quantidade final de trigo no elo $k$, descontando as perdas, em toneladas. 
A equação 3 quantifica a entrada inicial de trigo no elo $(k+1)$, baseado na quantidade final do elo anterior.

$$
Q I_{k+1}=Q F_{k}, \quad \forall k
$$

A equação 4 quantifica a perda econômica do elo $k$. Nesse caso, a perda econômica é baseada no conceito do custo de oportunidade com as vendas perdidas decorrentes das perdas físicas. Para o caso dos elos do transporte T1 e T2, ainda existe a perda monetária associada à perda física durante o transporte.

$$
\begin{aligned}
& \text { PEconomica }_{k} \\
& =\left\{\begin{array}{cc}
\text { se } k=\text { transp T1 ou transp T2, } & \left(\text { PV }+ \text { Frete }_{k}\right) \times \text { PFisica }_{k}, \\
\text { Caso contrário, } & \text { PV } \times \text { PFisica }_{k}
\end{array}, \quad \forall k\right.
\end{aligned}
$$

Onde:

PEconomica $_{k}$ é a perda econômica do elo $k$, em $\mathrm{R} \$$;

$P V$ é o preço médio de venda/comercialização de trigo no RS, em R $\$ / t$. Nesse caso, foi adotado o valor de $\mathrm{R} \$ 550,00$ por tonelada para a região do RS (CEPEA, 2014); Frete $_{k}$ é o preço do frete rodoviário no elo $k$, em $\mathrm{R} \$ /$ t. Nesse caso, os preços médios de frete rodoviário para T1 são $\mathrm{R} \$ 15,00$ por tonelada, enquanto que para T2 são $\mathrm{R} \$ 45,00$ por tonelada - tais informações foram baseadas nos preços médios de fretes praticados no RS para trigo em 2014, com dados observados no Sifreca/Esalq-USP para os diferentes trajetos (SIFRECA, 2015).

As equações 5, 6 e 7 ilustram a perda econômica total, física total e física relativa da cadeia de suprimentos do trigo.

$$
\begin{aligned}
& \begin{array}{c}
\text { PEconomicaTotal }=\sum_{k} \text { PEconomica } \\
\text { PFisicaTotal }
\end{array} \\
& =\sum_{k} \text { PFisica }_{k} \\
& \text { PFisicaTotalRelativa }=\left(\frac{\sum_{k} \text { PFisica }_{k}}{Q I_{k="} \text { fazenda" }^{\prime \prime}}\right)
\end{aligned}
$$


Onde:

PEconomicaTotal é a perda econômica total na cadeia de suprimentos do trigo, em $\mathrm{R} \$$

PFisicaTotal é a perda física total na cadeia de suprimentos do trigo, em toneladas; PFisicaTotalRelativa é a perda física percentual da cadeia de suprimentos do trigo, considerando todo o abastecimento para moageiras, em percentual.

\section{Resultados}

O foco do estudo foi o de mensurar as perdas existentes na logística do trigo no Rio Grande do Sul, e as entrevistas realizadas tiveram importância singular para concretização dos objetivos.

Os resultados são apresentados em três partes. A primeira parte diz respeito à caracterização da cadeia logística do Rio Grande do Sul, descrevendo o papel dos agentes na logística do trigo, os principais fluxos do produto, os modos de transporte e os tipos de veículos utilizados. A segunda parte apresenta os resultados relativos às perdas existentes em cada um dos elos dessa cadeia. Finalmente, na terceira parte dos resultados, são sugeridas estratégias para redução de perdas na cadeia logística do trigo.

\subsection{Caracterização da cadeia logística do trigo do Rio Grande do Sul}

Esta seção apresenta os principais resultados levantados na pesquisa de campo, com enfoque na cadeia logística do trigo. Neste sentido, descreve o papel dos agentes na logística do trigo, caracteriza os principais fluxos do produto, os modos de transporte e os tipos de veículos utilizados. A Figura 1 apresenta os principais fluxos e agentes envolvidos na cadeia logística do trigo, com destaque para os fluxos considerados neste trabalho para efeitos de estimativa das perdas, quais sejam: "fazenda $\rightarrow$ transporte T1 (fluxo logístico de trigo entre fazendas e cooperativa) $\rightarrow$ cooperativa $\rightarrow$ transporte $\mathrm{T} 2$ (fluxo logístico de trigo entre cooperativa e moinhos) $\rightarrow$ moinhos". 
Figura 1 - Principais fluxos de movimentação do trigo

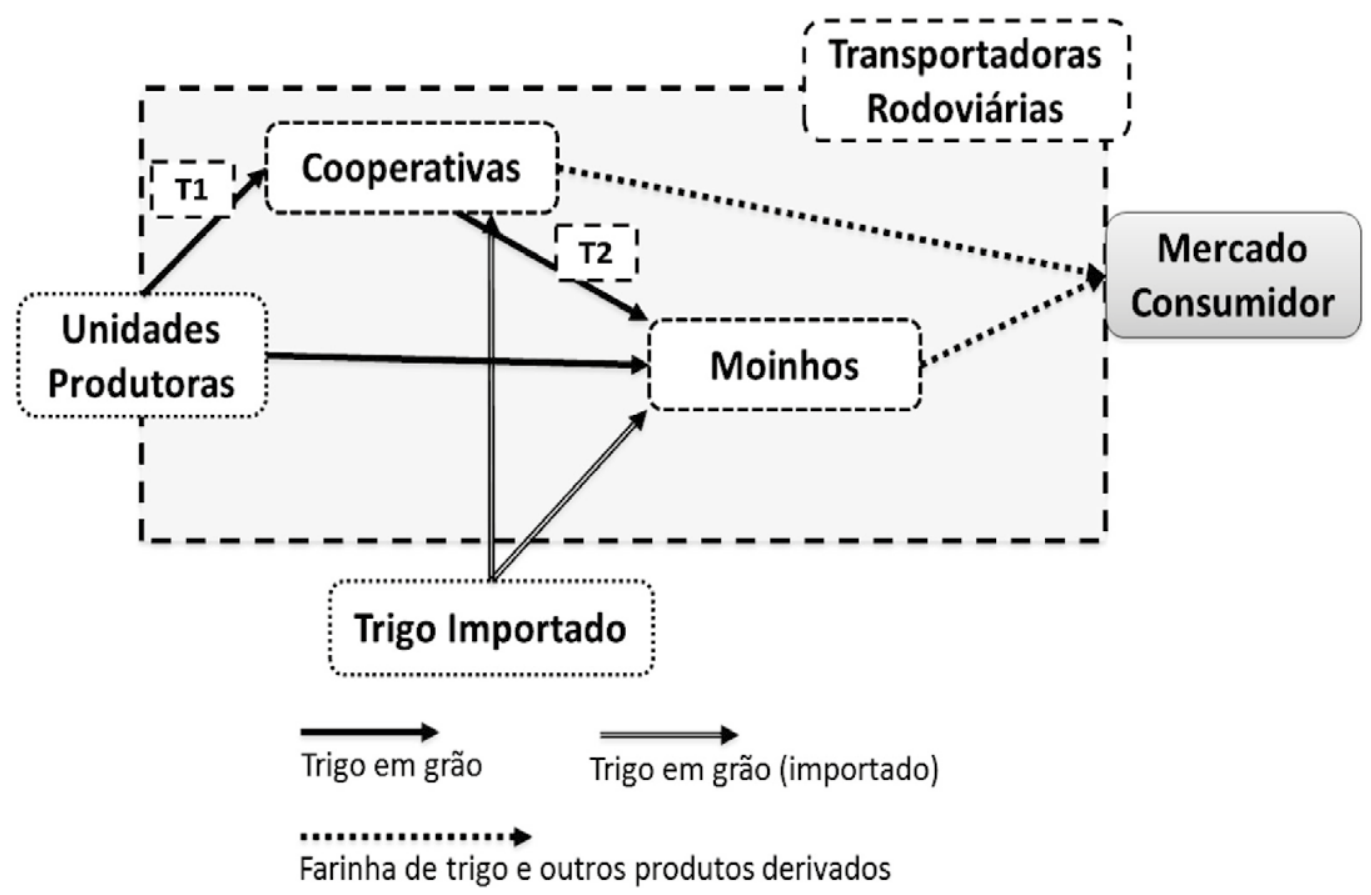

Fonte: elaborada pelos autores.

Um primeiro e importante fluxo diz respeito ao trigo em grão que sai da unidade produtora e chega até as cooperativas. Tal fluxo entre produtores e cooperativas ficou bastante evidenciado no trabalho de campo realizado, em função do elevado volume movimentado. Os produtores rurais, na maioria das vezes, vendem a sua produção para as cooperativas localizadas próximas à região de produção, caracterizando, portanto, movimentações por rotas relativamente curtas e envolvendo volumes significativos do produto. Em geral, a distância média percorrida pelos veículos carregados de trigo entre as fazendas produtoras e as cooperativas é curta (entre 20 e 25 quilômetros). Nesses casos, é comum o produtor assumir a responsabilidade pelo transporte até as cooperativas. Na sequência, as cooperativas acabam comercializando parte do trigo com os moinhos.

Um segundo fluxo, a partir da unidade produtora, segue em direção aos moinhos. Essa transação ocorre com uma frequência inferior, sendo observada apenas em casos envolvendo produtores maiores, que apresentam condições para o armazenamento e a padronização do produto. No moinho, o trigo em grão é processado, 
sendo transformado em farinha e farelo de trigo. A farinha de trigo é destinada para a elaboração de produtos para a alimentação humana. Em geral, os moinhos de grande porte costumam ter suas próprias linhas de produto para venda, tais como massas e biscoitos, além da produção de misturas para panificação que irão para outros beneficiadores, como padarias. Já o farelo de trigo é destinado à alimentação animal e é considerado, devido ao seu menor valor agregado, um subproduto da produção de farinha de trigo. Durante essa etapa de processamento, ocorre a mistura do trigo em grão importado ao trigo nacional. Em geral, o trigo importado possui maior resistência a temperaturas de fermentação, maior concentração de proteínas e é considerado de maior qualidade, devido a seu tamanho e peso maiores.

Nesses dois fluxos do transporte do trigo em grão a partir da unidade produtora, a movimentação é realizada utilizando-se exclusivamente do modal rodoviário. Particularmente sobre a operação de transporte, é comum a utilização de veículos próprios, sendo as transportadoras rodoviárias contratadas apenas quando há um volume excedente ou não há frota própria. No caso da execução do transporte via agentes terceiros, a reputação e confiança são fatores importantes na determinação dessa contratação, dado que os motoristas contratados são da mesma região da fazenda e cooperativa. Cabe destacar que não ocorre a pesagem dos veículos na fazenda.

$\mathrm{Na}$ cooperativa, o trigo pode ser processado ou, alternativamente, vendido para um moinho ou trader (neste último caso, para comercializações sentido exportação). O processamento pela própria cooperativa pode ser observado no mercado, porém o mais comum é a venda do trigo para os moinhos, os quais irão processar o grão e comercializar a farinha de trigo e outros derivados do grão, conforme mencionado anteriormente.

De fato, o trigo direcionado aos moinhos é oriundo, majoritariamente, das cooperativas. Além disso, conforme já indicado, uma parte do trigo é importado, e o restante é adquirido de grandes produtores locais que possuem uma infraestrutura de armazenagem.

Com capacidade para padronizar o trigo em termos de umidade e de impurezas, por exemplo, as cooperativas têm um papel muito importante no suprimento de trigo dos moinhos. Dessa forma, a movimentação das cargas ocorre somente com a utilização do modal rodoviário e, geralmente, os moinhos são os responsáveis pelo transporte do produto. É comum, nesse caso, os moinhos utilizarem frota própria para a distribuição desse volume de carga, e a fluidez do excedente ocorre pela contratação de transportadoras rodoviárias. 
Muita importância é dada para a qualidade do trigo que chega ao moinho, e os padrões de impurezas, de umidade e de peso hectolitro, por exemplo, necessitam ser respeitados, não ultrapassando os limites prescritos no contrato entre os dois agentes. Havendo diferenças

entre as cláusulas contratuais e o produto recebido no moinho, a carga não é aceita por esse segundo agente, retornando para a cooperativa, a qual irá arcar com os custos de transporte.

Para melhorar a qualidade do trigo a ser processado, os moinhos misturam trigo importado ao nacional. Os principais países de origem do trigo importado pelo Brasil são a Argentina, o Uruguai, o Paraguai, os Estados Unidos e o Canadá. Na prática, a exigência por esse produto é dos próprios clientes do mercado, os quais pagam um preço mais elevado por uma farinha de qualidade melhor. Nesse caso, os moinhos compram trigo estrangeiro de um agente intermediário, geralmente uma trader, a qual é responsável pelo transporte do trigo até o Brasil.

O trigo importado chega ao Rio Grande do Sul por vias marítimas, entrando no país majoritariamente pelo Porto de Rio Grande. A Lagoa dos Patos tem um papel importante para o transporte hidroviário desse produto até o interior do estado, principalmente na região de Porto Alegre, a partir da qual o trigo é transportado até os moinhos por caminhões (frota do próprio moinho ou contratados no mercado). Assim, a multimodalidade é frequentemente utilizada para transportar o trigo importado até as cooperativas ou os moinhos.

Com o trigo importado no moinho, a mistura com o trigo nacional e o processamento é feito de acordo com a especificidade dos pedidos dos clientes do moinho. Após o processo industrial, a farinha de trigo, bem como suas variações de produtos finais, é destinada para atender a demanda do mercado (atacadista e varejista). O carregamento de farinha de trigo a granel nos caminhões não é uma prática comum, sendo mais frequente o carregamento do produto ensacado.

\subsection{Perdas na cadeia logística do trigo}

As perdas do trigo em grãos serão quantificadas ao longo dos seguintes estágios da cadeia logística: colheita (nas unidades produtoras), armazenagem (nas cooperativas), processamento (nos moinhos de trigo) e transporte (das unidades produtoras para as cooperativas, e das cooperativas para os moinhos). Os demais fluxos existentes não são considerados nessa análise de contabilização das perdas.

Inicialmente, nas propriedades agrícolas, estima-se uma perda da ordem de $6 \%$ da produção durante o processo de colheita. Entre os fatores dessa perda, 
destacam-se as condições inadequadas dos implementos utilizados na colheita, tais como a regulagem do maquinário, bem como a velocidade na qual a colheita é realizada. Condições edafoclimáticas adversas também acabam contribuindo para esse resultado.

Em seguida, as perdas estimadas no transporte do trigo em grão das fazendas para as cooperativas (T1) representam cerca de $0,5 \%$ do total carregado no caminhão. Destaca-se que tal mensuração é difícil de ser realizada e envolve um certo grau de incerteza pelo fato de não haver pesagem dos veículos nas fazendas. Os agentes entrevistados alegaram que as perdas nesse transporte, apesar de não serem efetivamente contabilizadas, existem, e só não são mais representativas em termos percentuais em função da proximidade entre origem (unidades produtoras) e destino (cooperativas). Características marcantes desse transporte estão relacionadas à utilização da capacidade de carga dos veículos (geralmente com sobrepeso) e às condições precárias das estradas (geralmente de terra).

Na cooperativa, o trigo é armazenado e padronizado antes de ser comercializado com os moinhos. Nesse processo de armazenamento e de carregamento para o moinho, as condições de infraestrutura de parte das cooperativas não estão nos níveis ideais, e mesmo os controles de qualidade aplicados não são suficientes para anular os níveis de perdas. Além disso, a incidência de pragas e roedores acaba por contribuir com as perdas nesta etapa. Há, portanto, perdas no armazenamento do grão que representam $5 \%$ do volume total que chega nas cooperativas, conforme foi identificado a partir das entrevistas realizadas. Deve-se destacar que, nas entrevistas, ficou claro que as perdas no armazenamento são variáveis entre diferentes regiões.

No transporte do trigo da cooperativa até os moinhos (T2), a existência de estrutura de pesagem nas duas pontas permite que haja um controle mais efetivo do volume perdido nesta operação. A tolerância máxima, nesse caso, é que ocorra uma perda de $0,2 \%$ do peso carregado no veículo. Ultrapassando esse limite, a transportadora é responsável por arcar com a diferença verificada. Na prática, é comum que as perdas ultrapassem um pouco esse limite estabelecido. A partir da pesquisa de campo, verificou-se que as perdas são, em média, de $0,3 \%$ do volume total carregado no veículo. Tal nível de perda é inferior ao da primeira etapa do transporte (entre produtor e cooperativa), devido ao fato de que: (a) nesse caso há uma predominância de estradas asfaltadas, e (b) a operação de carregamento na cooperativa é mais técnica e eficiente do que a operação de carregamento na fazenda.

Finalmente, os agentes consultados afirmaram que não há perdas significativas durante o processo de industrialização do trigo nos moinhos, principalmente em função do processo de adição de água durante a moagem. 
A Figura 2 sintetiza os resultados estudados relativos às perdas em cada um dos elos do fluxo da cadeia do trigo no Rio Grande do Sul.

Figura 2 - Estimativa de perdas na cadeia logística do trigo
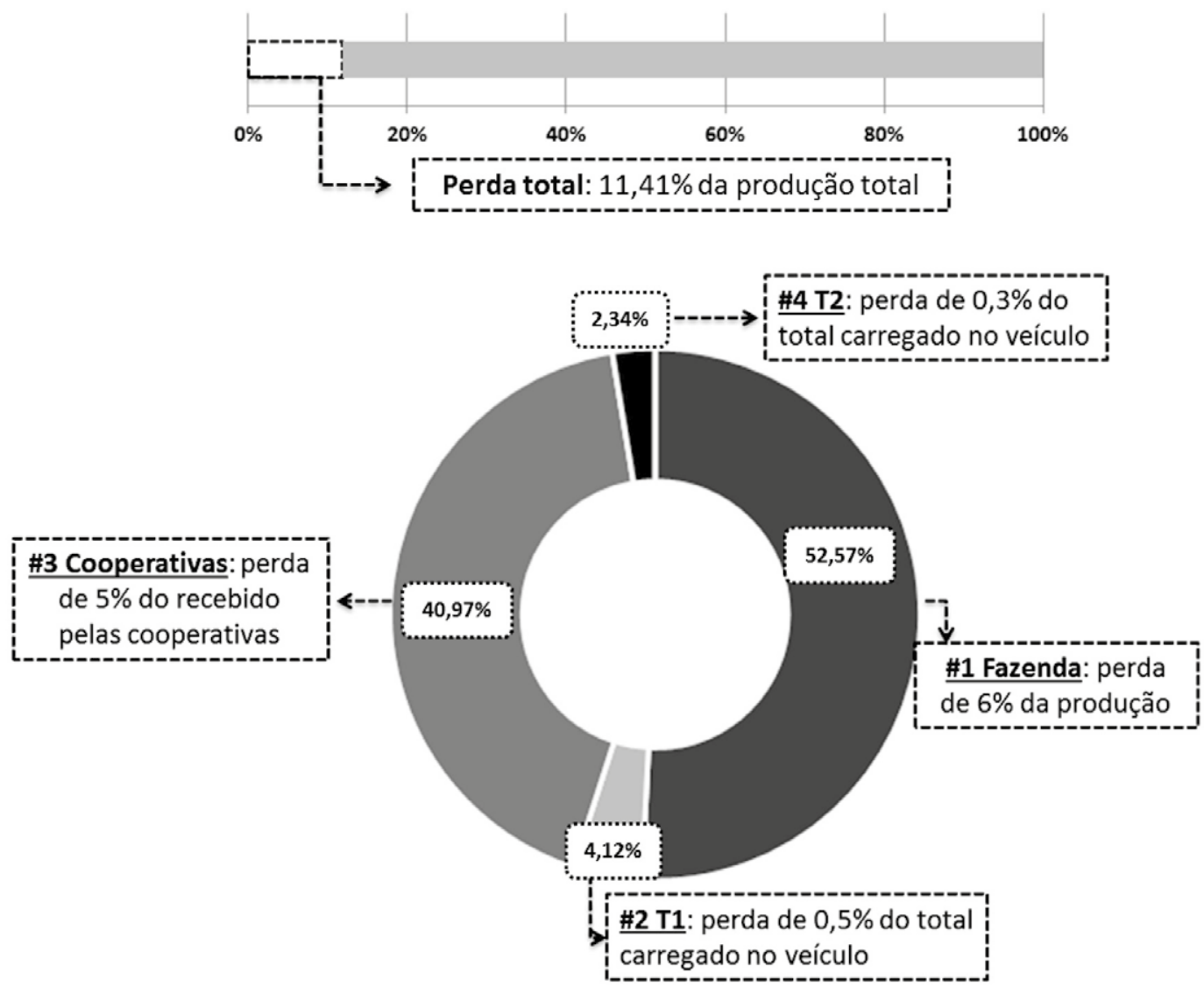

Fonte: elaborado pelos autores com base nos resultados da pesquisa.

As perdas totais neste fluxo entre as propriedades rurais e os moinhos correspondem a $11,41 \%$ do trigo em grão produzido. Destacam-se neste contexto, as perdas na colheita e na armazenagem junto às cooperativas (que respondem por 93,55\% das perdas totais). As operações de transporte (T1 e T2) representam 6,45\% das perdas totais neste fluxo.

Considerando que os moinhos do Rio Grande do Sul processaram 1,68 milhões de toneladas de trigo em 2013 (ABITRIGO, 2015), essas perdas representam cerca de 200 mil toneladas anuais. Dessa forma, perde-se um volume suficiente 
para alimentar quase 3.000 pessoas, e para carregar cerca de 6.700 carretas com trigo, que não chegam ao destino final. Nessa contabilidade, ainda precisam ser acrescidas, por exemplo, as perdas existentes nas etapas de transbordo de carga no processo de importação do trigo e nas etapas posteriores ao processamento do trigo pelos moinhos.

É importante salientar também que, ao longo de toda a cadeia, as perdas não são visualizadas como um problema a ser resolvido. Consideradas como naturais no processo de compra, venda e movimentação do produto, são poucos os agentes do mercado que estão preocupados com a redução dos níveis de perdas. Isso ocorre porque os números, quando conhecidos, são visualizados de forma isolada, e não integrados tal como numa cadeia de suprimentos. Tal posicionamento dos agentes em relação ao tratamento das perdas também é observado em outras cadeias agroindustriais no país.

Quando convertidas em unidades monetárias, essas perdas não são desprezíveis, tal como pode ser visualizado na Tabela 4, a qual ilustra as estimativas de perdas físicas e econômicas na cadeia de suprimentos das moageiras do RS.

Tabela 4 - Estimativas das perdas físicas e econômicas dos elos da cadeia de suprimentos das moageiras de trigo no RS (CST)

\begin{tabular}{l|r|r|r|r|r|r}
\hline \multicolumn{1}{c}{$\begin{array}{l}\text { Variáveis / } \\
\text { Elos da CST }\end{array}$} & Unidade & Fazenda & Transp. T1 & Cooperativa & Transp. T2 & Total \\
\hline $\begin{array}{l}\text { Quantidade } \\
\text { inicial }\end{array}$ & $\mathrm{t}$ & 1.896 .442 & 1.782 .656 & 1.773 .742 & 1.685 .055 & - \\
$\begin{array}{l}\text { Perda } \\
\text { Perda total }\end{array}$ & $\mathrm{t}$ & 113.787 & 8.913 & 88.687 & 5.055 & 216.442 \\
$\begin{array}{l}\text { Quantidade final } \\
\text { Preço de } \\
\text { comercialização }\end{array}$ & $\mathrm{t}$ & 1.782 .656 & 1.773 .742 & 1.685 .055 & 1.680 .000 & - \\
$\begin{array}{l}\text { Preço do frete } \\
\text { rodoviário }\end{array}$ & $\mathrm{R} \$ \mathrm{t} / \mathrm{t}$ & 550 & 550 & 550 & 550 & - \\
$\begin{array}{l}\text { Perda } \\
\text { econômica }\end{array}$ & $\mathrm{R} \$$ & 62.582 .589 & 5.036 .002 & 48.777 .913 & 3.007 .823 & 119.404 .327 \\
\hline
\end{tabular}

Fonte: elaborada pelos autores.

As perdas econômicas por elo são: fazenda ( $\mathrm{R} \$ 62$ milhões), transporte $\mathrm{T} 1$ ( $\mathrm{R} \$ 5$ milhões), cooperativa ( $\mathrm{R} \$ 48,7$ milhões) e transporte $\mathrm{T} 2$ ( $\mathrm{R} \$ 3$ milhões). A soma total das perdas econômicas em cada elo totaliza $R \$ 119,4$ milhões decorrentes do custo 
de oportunidade das vendas perdidas e das contratações de fretes desnecessárias, totalizando uma perda física total de 216,4 mil toneladas e relativa de $11,41 \%$.

Nesse sentido, tais indicadores evidenciam a necessidade da constante busca por alternativas que as minimizem em cada etapa da cadeia logística. Além disso, ao reduzir as perdas, também se aumenta a disponibilidade de alimento, consequentemente contribuindo para o aumento da segurança alimentar e para a redução dos níveis de pobreza rural local.

\subsection{Estratégias para redução de perdas na cadeia logística do trigo}

Entre as possíveis estratégias existentes para a redução dos níveis de perdas no pós-colheita, existem aquelas que podem ser adotadas pelos agentes envolvidos na cadeia logística, e outras que dependem de uma intervenção mais direta do governo, através da adoção de políticas públicas. A seguir, são sugeridas e discutidas algumas das medidas principais levantadas no estudo. Tais medidas destacam-se como as mais evidentes e importantes em termos de impactos na redução das perdas.

1. Gestão das perdas e metas de redução: mensurações periódicas das perdas é o primeiro passo na busca pela minimização das mesmas. O estudo mostra que grande parte dos agentes atuantes nesta cadeia agroindustrial (assim como em outras), não investem na contabilização, acompanhamento e gestão das perdas. A partir de um sistema de gestão, mesmo que simples, é possível estabelecer baselines, identificar etapas mais críticas e definir metas de redução de perdas ao longo da cadeia de suprimento.

2. Atenção aos níveis de serviço de transporte: a qualidade do serviço de transporte, seja através do tipo de veículo utilizado, seja através das características de carregamento (tal como respeito aos limites dos veículos), pode trazer contribuições interessantes para redução das perdas. A receita advinda com tal redução pode mais do que compensar um frete mais elevado em função do nível de serviço diferenciado, no caso de transporte contratado. Por outro lado, no caso de frota própria, pode auxiliar na aquisição de veículos mais novos e mais eficientes.

3. Investimentos público e privado em:

a) infraestrutura de armazenagem: a falta de infraestrutura adequada de armazenagem é a principal fonte de perdas, principalmente em países em desenvolvimento. Tecnologias que permitam o armazenamento em condições herméticas protegem o grão de umidade e pestes. Além de 
evitar perdas, o armazenamento permite que o produtor espere o momento mais atrativo no mercado para vender o grão, gerando, assim, uma receita mais elevada.

b) infraestrutura de transporte: uma infraestrutura de transporte mais adequada pode contribuir muito para a redução dos níveis de perdas. Neste contexto, destaca-se a importância de rodovias em boas condições de conservação, além de modais alternativos de transporte.

\section{Considerações finais}

Este artigo caracterizou a cadeia logística do trigo no Rio Grande do Sul e, em especial, mensurou as perdas existentes ao longo de cada etapa desta cadeia logística, no fluxo entre os produtores rurais e os moinhos. As principais contribuições deste trabalho estão relacionadas a basicamente quatro tópicos.

A primeira contribuição diz respeito à quantificação das perdas físicas e econômicas de trigo em grão no estado do Rio Grande do Sul. O estudo verificou que $11,41 \%$ do trigo é perdido nas etapas logísticas analisadas, o que equivale a cerca de 216,4 mil toneladas/ano. Esta quantidade de trigo seria suficiente para alimentar quase 3 mil pessoas/ano, e equivale a cerca de 6.700 caminhões que deixam de chegar ao destino final. Outro resultado importante, diz respeito a monetização das perdas físicas decorrentes das vendas perdidas, a qual totaliza um valor de $\mathrm{R} \$ 119,4$ milhões.

A segunda contribuição é que, além das perdas físicas totais, foi possível identificar as perdas relativas a cada elo da cadeia logística do trigo analisada. Neste sentido, os maiores níveis de perda ocorrem no pós-colheita, ainda na fazenda (cerca de 6\%) e no armazenamento nas cooperativas (aproximadamente 5\%). Assim, as perdas ocorridas nestas etapas logísticas correspondem a $93,55 \%$ das perdas totais. Já as perdas no transporte dependem do segmento a ser interligado, mas atingem, no máximo, 0,5\% (o que represent 6,45\% das perdas totais). As perdas ocorridas no "T1" (entre a unidade produtora e as cooperativas) são superiores às verificadas no "T2" (entre cooperativas e moinhos). Esta diferença ocorre devido às diferenças no grau de incerteza envolvido na quantificação e, principalmente, às condições distintas do transporte verificadas nestes dois segmentos (tanto em termos dos veículos, quanto das condições de rodovias envolvidas).

Observou-se também que as perdas possuem significados bastante distintos entre os agentes da cadeia logística do trigo no RS. Não há uma preocupação evidente dos produtores em relação a essa questão. De forma geral, os produtores não 
têm referência do quanto se perde no trajeto entre a fazenda e a cooperativa ou o moinho, dado que não é feita pesagem do caminhão na fazenda, mas apenas nas unidades receptoras. Neste sentido, o estudo indicou que a preferência diz respeito à máxima utilização do veículo nas viagens (provocando sobrepeso nestes trajetos) vis-à-vis um nível de serviço adequado que resulte em menores taxas de perda. Por outro lado, atenção maior às perdas é dada nos fluxos entre cooperativas e moinhos, por exemplo. Devido à pesagem do veículo no trajeto entre moinhos e cooperativas, o conhecimento e a quantificação se tornam mais evidentes. As perdas quantitativas são consideradas, assim, perdas monetárias e, se ocorrem, são descontadas do transportador.

Finalmente, a partir dos resultados, foi possível fazer uma série de sugestões para se reduzir as perdas. Tais sugestões referem-se a estratégias voltadas tanto para políticas públicas, dentre as quais destacam-se aquelas voltadas para melhoria da infraestrutura de transporte, quanto para o gerenciamento estratégico da cadeia do trigo propriamente dita, tais como introdução de uma cultura de mensuração e definição de metas de redução, a partir de sistema de gestão de perdas. 


\title{
Measurement of the post-harvest losses in wheat mills supply logistic chain in Rio Grande do Sul
}

\begin{abstract}
This paper is mainly intended to measure losses (physical and economic) along the wheat supply chain in Rio Grande do Sul (RS). Based on a field research and a questionnaire applied to representative agents, the wheat supply chain in the state of RS was characterized and loss rates in each stage of that chain were quantified. Typically, losses during transportation in the domestic market account for about $11.418 \%$ of the total amount of wheat grain that leaves the farms. Losses during harvest and storage in cooperatives $(93.55 \%$ of total losses) stand out in this context. This amount of loss represents that $\mathrm{R} \$ 119.4$ milion are lost between these stages of the logistic chain. Based on the results obtained in this study, strategies are suggested to reduce food losses in different links of the logistics chain.
\end{abstract}

Keywords: Food security. Post-harvast losses. Supply chain. Wheat.

\section{La medición de las pérdidas en la cadena logística de los molinos de trigo en Rio Grande do Sul}

\section{Resumen}

Este documento está destinado principalmente para medir las pérdidas (físicos y económicos) de la cadena de suministro de trigo en Rio Grande do Sul (RS). Basado en una investigación de campo y un cuestionario aplicado a los agentes representativos, la cadena de suministro de trigo en el estado de RS se caracterizó y las pérdida en cada etapa de la cadena que se cuantificaron. Las pérdidas durante el transporte en el mercado nacional representan aproximadamente el 11,418\% de la cantidad total de grano de trigo que sale de las granjas. Las pérdidas durante la cosecha y el almacenamiento en las cooperativas (93,55\% de las pérdidas totales) se destacan en este contexto. La cantidad total de pérdida que representa $\mathrm{R} \$ 119,4$ milones. Basándose en los resultados obtenidos en este estudio, se sugieren estrategias para reducir las pérdidas de trigo en diferentes eslabones de la cadena logística.

Palabras clave: Cadena de suministros. Perdidas en poscosecha. Seguridad alimentaria. Trigo. 


\section{Referências}

ABITRIGO - ASSOCIAÇÃO BRASILEIRA DA INDÚSTRIA DO TRIGO. Estatísticas. Disponível em: <http://www.abitrigo.com.br/index.php?mpg=09.01.00>. Acesso em: 25 jun. 2015.

BELIK, W.; CUNHA, A. R. A. A.; COSTA, L. A. Crise dos alimentos e estratégias para a redução do desperdício no contexto de uma política de segurança alimentar e nutricional no Brasil. Planejamento e Políticas Públicas, Brasília, n. 38, p. 108-132, jan./jun. 2012.

BOURNE, M. C. Post harvest food losses - the neglected dimension in increasing the world food supply. Cornell International Agriculture Mimeograph 53: Ithaca, 1977.

CAIXETA-FILHO, J. V. Losses in the Transportation of Fruit and Vegetables: a Brazilian Case Study. International Journal of Logistics: Research and Applications, v. 2, n. 3, p. 325-341, 1999. CEPEA - CENTRO DE PESQUISA ECONÔMICAS AVANÇADAS. Indicadores de preços de comercialização de trigo. Piracicaba: CEPEA, 2014. Disponível em: <http://cepea.esalq.usp.br/trigo/>. Acesso em: 25 jun. 2015.

CONAB - COMPANHIA NACIONAL DE ABASTECIMENTO. Levantamento de safra. Brasília: CONAB, 2014. Disponível em: <http://www.conab.gov.br/conteudos.php?a=1253\&>. Acesso em: 25 jun. 2015.

CONFEDERAÇÃO NACIONAL DO TRANSPORTE. Relatório Gerencial: Pesquisa CNT de Rodovias 2014. Brasília: CNT, 2014.

FOOD AND AGRICULTURE ORGANIZATION. Statistics division. Roma: FAO, 2015. Disponível em: <http://faostat3.fao.org/home/E>. Acesso em: 25 jun. 2015.

GAMEIRO, A. H. et al. Modelagem e gestão das perdas no suprimento de tomates para processamento industrial. Gestão \& Produção, São Carlos, v. 15, n. 1, p. 101-115, abr. 2008.

GIL, A. C. Métodos e Técnicas de Pesquisa Social. 5. ed. São Paulo: Atlas, 1999.

HAIR JR., J. F. et al. Fundamentos de métodos de pesquisa em administração. Trad. Lene Belon Ribeiro. Porto Alegre: Bookman, 2005.

IBGE - INSTITUTO BRASILEIRO DE GEOGRAFIA E ESTATÍSTICA. Censo agropecuário 2006. Brasília: IBGE, 2006. Disponível em: <http://www.ibge.gov.br/home/estatistica/economia/ agropecuaria/censoagro/2006/>. Acesso em: 25 jun. 2015.

LIPINSKI, B. et al. Reducing Food Loss and Waste. Working Paper, World Resources Institute, p. 1-39, jun. 2013.

MARSCHALL, C. R. Motivações para o Cooperativismo na Pequena Propriedade. Organizações $\&$ Sociedade, Salvador, v. 16, n. 49, p. 287-306, jun. 2009.

MAPA - MINISTÉRIO DA AGRICULTURA, PECUÁRIA E ABASTECIMENTO. Trigo. Brasília: MAPA, 2015. Disponível em: <http://www.agricultura.gov.br/vegetal/culturas/trigo>. Acesso em: 25 jun. 2015.

PARFITT, J.; BARTHEL, M.; MACNAUGHTON, S. Food waste within food supply chains: quantification and potential for change to 2050. Philosophical Transactions of the Royal Society, v. 365 , p. $3065-3081,2010$. 
PEROSA, J. M. Y.; SILVA, C. S.; PEROSA, J. M. Y. Avaliação das perdas de manga no mercado varejista da cidade de Botucatu-SP. Revista Brasileira de Fruticultura, Jaboticabal, v. 31, n. 3, p. 732-738, 2009.

SEVERINO, A. J. Metodologia do Trabalho Científico. 23. ed. São Paulo: Cortez, 2007.

SIFRECA - SISTEMA DE INFORMAÇÕES DE FRETES. Indicadores de preço de fretes rodoviários. Piracicaba: SIFRECA, 2015. Disponível em: <http://log.esalq.usp.br/sifreca>. Acesso em: 25 jun. 2015.

SILVA, A. A. L. et al. Modelagem das perdas causadas por Sitophilus zeamais e Rhyzopertha dominica em trigo armazenado. Revista Brasileira de Engenharia Agrícola e Ambiental, Campina Grande, v. 7, n. 2, p. 292-296, 2003a.

SILVA, A. A. L. et al. O. Avaliação econômica das perdas de banana no mercado varejista: um estudo de caso. Revista Brasileira de Fruticultura, Jaboticabal, v. 25, n. 2, p. 229-234, 2003b.

TOFANELLI, M. B. D. et al. Perdas de frutas frescas no comércio varejista de Mineiros-GO: um estudo de caso. Revista Brasileira de Fruticultura, Jaboticabal, v. 29, n. 3, p. 513-517, 2007. 